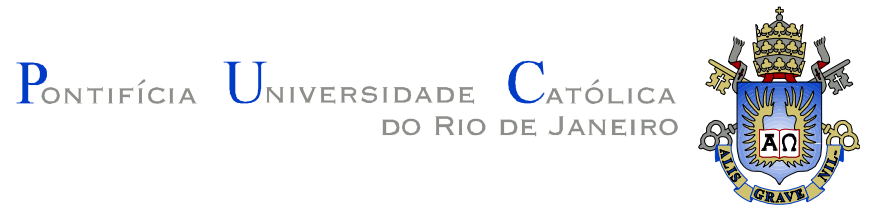

Marília Saldanha da Silva

De(s)colar de casa: dilemas contemporâneos

dos casais de aeronautas

Dissertação de Mestrado

Dissertação apresentada como requisito parcial para obtenção do grau de Mestre pelo Programa de Pós-graduação em Psicologia Clínica do Departamento de Psicologia da PUC-Rio.

Orientador: Bernardo Jablonski

Rio de Janeiro

Fevereiro de 2010 
Marília Saldanha da Silva

\section{De(s)colar de casa: dilemas contemporâneos dos casais de aeronautas}

Dissertação apresentada como requisito parcial para obtenção do grau de Mestre pelo Programa de Pós-graduação em Psicologia Clínica do Departamento de Psicologia da PUC-Rio. Aprovada pela Comissão Examinadora abaixo assinada:

Prof. Bernardo Jablonski

Orientador

Departamento de Psicologia - PUC-Rio

Prof $^{\text {a. }}$ Andrea Seixas Magalhães Departamento de Psicologia - PUC-Rio

\section{Prof $^{\text {a. }}$ Maria Lucia Rocha-Coutinho} Eicos-UFRJ

Prof. Paulo Fernando Carneiro de Andrade Coordenador Setorial de Pós-Graduação e pesquisa do Centro de Teologia e Ciências Humanas - PUC-Rio

Rio de Janeiro, 26 de fevereiro de 2010 
Todos os direitos reservados. É proibida a reprodução total ou parcial do trabalho sem autorização da universidade, da autora e do orientador.

\section{Marília Saldanha da Silva}

Graduou-se em Psicologia em 1998 pela UNESA (Universidade Estácio de Sá). Fez formação em Psicossomática Reichiana pelo Instituto de Psicoterapia Reichiana em 2001. Atua na clínica individual em contexto privado.

Ficha Catalográfica

Silva, Marília Saldanha da

De(s)colar de casa : dilemas contemporâneos dos casais de aeronautas / Marília Saldanha da Silva ; orientador: Bernardo Jablonski. - 2010.

108 f. ; $30 \mathrm{~cm}$

Dissertação (Mestrado em Psicologia)-Pontifícia Universidade Católica do Rio de Janeiro, Rio de Janeiro, 2010.

Inclui bibliografia

1. Psicologia - Teses. 2. Divisão de tarefas domésticas. 3. Relações de gênero. 4. Aeronautas. 5. Contemporaneidade. I. Jablonski, Bernardo. II. Pontifícia Universidade Católica do Rio de Janeiro. Departamento de Psicologia. III. Título.

CDD: 150 


\section{Agradecimentos}

Ao André com quem aprendi de verdade o que é casar...

Aos meus pais que me ensinaram a valorizar o estudo e me estimularam a ser uma mulher independente.

Talvez seja estranho agradecer aos cães...menciono apenas o quão alentador foi ter a presença constante de meu pequeno shitzu sob a escrivaninha enquanto digitava.

Ao meu orientador Bernardo Jablonski, por acolher meu projeto e abrir a janela para as inúmeras pesquisas a que tive acesso.

Aos casais que aceitaram dar uma pausa em suas vidas voadas (lembrem-se aeronautas não correm, voam) e soltaram o verbo sobre a conciliação entre família e trabalho.

Aos ex-colegas da Varig que abriram prontamente suas agendas e rastrearam na memória, possíveis indicações de casais para as entrevistas.

À Tatiana Charpinel que super disponível compartilhou suas experiências de entrevistas em conversa telefônica.

À Nataly Mariz com quem eu vi surgir uma amizade à medida que compartilhávamos nossas experiências do estágio de docência e as maravilhosas aulas de francês.

Aos queridos colegas de mestrado com quem compartilhei anseios, dúvidas, dicas, diversão.

Aos professores da pós-graduação do departamento de psicologia, em especial à professora Teresinha Féres-Carneiro.

Aos funcionários da secretaria do departamento de psicologia.

À Capes e à PUC-Rio, pelo apoio. 


\section{Resumo}

Silva, Marília Saldanha da; Jablonski, Bernardo. De(s)colar de casa: dilemas contemporâneos dos casais de aeronautas. Rio de Janeiro, 2010. 108p. Dissertação de Mestrado - Departamento de Psicologia, Pontifícia Universidade Católica do Rio de Janeiro.

O presente estudo procura examinar a questão da desigualdade de gênero na divisão de tarefas domésticas e responsabilidades familiares entre membros de casais de aeronautas, profissionais da aviação comercial (comissários e pilotos). Procura-se investigar neste subgrupo como ocorre a conciliação entre a vida familiar e o trabalho de turnos alternantes. Utiliza-se como referencial básico a contribuição de cientistas sociais em seus estudos acerca das relações de gênero na contemporaneidade. Homens e mulheres trabalham cada vez mais em horário integral e se veem divididos diante de propostas igualitárias de relacionamento em contraposição a práticas mais tradicionais. Parece que a transformação das mentalidades nas relações de gênero foi insuficiente no que diz respeito a uma divisão mais igualitária das tarefas domésticas. A lacuna deixada pelas mulheres na vida privada, com sua entrada maciça no mercado de trabalho, não foi ocupada por outros, senão por elas próprias, que se dividiram e se multiplicaram em muitas para poder conciliar família e profissão. Após uma revisão de literatura, foram realizadas entrevistas com quatro casais de aeronautas do Rio de Janeiro. Os dados obtidos nas entrevistas entraram em consonância com o que a literatura já vem discutindo sobre casais de outras categorias profissionais. As mulheres casadas e com filhos despendem mais tempo com o trabalho doméstico e com as responsabilidades familiares do que seus maridos. Diante desta constatação, percebe-se que a especialização de papéis ainda está fortemente ancorada nas ideologias de gênero tradicionais que regem os comportamentos de homens e mulheres contemporâneos, produzindo com isto um cenário desfavorável para ascensão profissional das mulheres e para um maior envolvimento dos homens com a vida familiar.

\section{Palavras-chave}

Divisão de tarefas domésticas; responsabilidades familiares; aeronautas; papeis de gênero; contemporaneidade. 


\section{Abstract}

Silva, Marília Saldanha da; Jablonski, Bernardo (Advisor). Take-off from home: contemporary dilemmas for crew members couples. Rio de Janeiro, 2010. 108p. MSc. Dissertation - Departamento de Psicologia, Pontifícia Universidade Católica do Rio de Janeiro.

The main subject of this study is the gender inequality in the division of household chores and child care between spouses who work as crew members in civil aviation (flight attendants and pilots). This study reports an investigation of the relationships of nonstandard work schedules and family balance. It is based on the several studies conducted by social scientists about gender relations in the contemporary society. Men and women are engaged in full time work and confronted with an egalitarian social discourse and traditional patterns of behavior. It seems that the shift regarding gender relations and more balanced divisions of household chores are still insufficient. Women joined the workforce dealing with multiple roles to balance household chores and career. After reviewing several academic books and articles, interviews with four middle class flight crew members' couples from Rio de Janeiro were conducted. The results were similar to other studies with couples from other professional categories: married women with children still do much more routine household chores than their husbands. The gender segregation of tasks associated with the traditional gender ideologies contribute to reinforcing the specialized roles, an unfavorable scenario for career development for women and greater involvement of men with family life.

\section{Keywords}

Divisions of household; crew members; gender relations; contemporariness 


\section{Sumário}

1- Introdução 9

2.- O mundo doméstico 17

$\begin{array}{ll}2.1 \text { - A importância das tarefas domésticas } & 17\end{array}$

$\begin{array}{ll}2.1 .1 \text { - Divisão das tarefas domésticas. } & 19\end{array}$

2.2 - A revolução industrial e a divisão sexual do trabalho 22

2.2.1 - O trabalho doméstico desnudado . 25

2.3 - Papéis de gênero no âmbito doméstico. 26

2.3.1 - Dona-de-casa-ainda-feliz-com-o-seu-papel? 26

2.3.2 - Donos-de-casa, por que não? 31

2.4 - Gestão do cotidiano $\quad 34$

3.- Des-igualdades de Gênero 38

3.1 - Feminismo contemporâneo: reviravolta na definição dos gêneros 38

3.2 - Definições e usos do termo "gênero" $\quad 40$

3.2.1 - Teorias de gênero $\quad 41$

3.2.2 - Ideologias de gênero: tradicional, igualitária, transicional 42

3.2.3 - Ideologias de gênero e o trabalho doméstico 45

3.2.4 - Homens "domesticados" versus homens "de verdade" 46

3.3 - O epicentro das desigualdades: o casamento contemporâneo 50

3.3.1 - O casamento dele $\quad 52$

3.3.2 - O casamento dela $\quad 53$

3.4 - Desigualdades no uso do tempo 54

3.5 - Desigualdades no compartilhamento parental. 58

$\begin{array}{ll}3.6 \text { - Igualdade relacional } & 60\end{array}$ 
4.- Vida familiar e trabalhos com horários fora do padrão e viagem: dilemas $\begin{array}{ll}\text { contemporâneos dos casais de aeronautas } & 62\end{array}$

4.1 - A mulher e o trabalho fora de casa 62

4.2 - Novos arranjos matrimoniais $\quad 64$

4.3 - Trabalhos com horários fora do padrão e viagens: repercussões nas

relações familiares e vida social $\quad 66$

4.3.1 - Entre pousos e decolagens: um cotidiano peculiar 72

4.3.2 - Efeitos na dinâmica familiar: conjugalidade e parentalidade em foco 74

5.- Estudo de campo $\quad 79$

$\begin{array}{ll}5.1 \text { - Participantes } & 79\end{array}$

$\begin{array}{lr}5.2 \text { - Instrumentos e procedimentos } & 80\end{array}$

5.3 - Análise dos dados obtidos $\quad 80$

$\begin{array}{ll}5.3 .1-\text { Cotidiano } & 80\end{array}$

5.3.2 - Divisão de tarefas domésticas $\quad 83$

$\begin{array}{lr}\text { 5.3.3 - Compartilhamento parental } & 88\end{array}$

$\begin{array}{ll}5.3 .4-\text { Lazer } & 90\end{array}$

6.- Considerações finais 93

$\begin{array}{ll}\text { Referências bibliográficas } & 100\end{array}$

$\begin{array}{ll}\text { Anexos } & 105\end{array}$

$\begin{array}{ll}\text { Anexo } 1 \text { - Consentimento livre e esclarecido } & 105\end{array}$

Anexo 2 - Dados dos participantes da pesquisa de campo 106

$\begin{array}{ll}\text { Anexo } 3 \text { - Roteiro das Entrevistas } & 107\end{array}$ 